Running Head: REPEAT MISSING CHILD REPORTS IN WALES

Accepted by Child Abuse $\&$ Neglect on $6^{\text {th }}$ November 2018 and published online on $21^{\text {st }}$ November 2018. (2019) Vol. 88, $107-117$

\title{
Repeat Missing Child Reports in Wales
}

\author{
Emma Hutchings ${ }^{a}$, Kevin D. Browne ${ }^{a}$, Shihning Chou ${ }^{a}, K_{\text {Kerry Wade }}^{b}$ \\ ${ }^{a}$ Centre for Forensic and Family Psychology, School of Medicine, University of \\ Nottingham, England, UK.

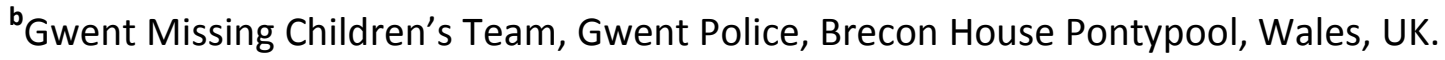

\section{Corresponding \\ author}

- E-mail: hutchingsel@gmail.com

- Postal address: Centre for Forensic and Family Psychology, School of Medicine,

University of Nottingham, Room B22, YANG Fujia Building, Jubilee Campus,

Wollaton Road, Nottingham, NG8 1BB, UK 


\title{
REPEAT MISSING CHILD REPORTS IN WALES
}

\author{
Repeat Missing Child Reports in Wales
}

There were approximately 306,000 reports of missing persons in the UK from 20122013, 64\% involved children (Bureau, 2014). The Association of Chief Police Officers (ACPO) defines missing as: "Anyone whose whereabouts cannot be established and where the circumstances are out of character or the context suggests the person may be subject of crime or at risk of harm to themselves or another" (ACPO, 2013). Children go missing for a variety of reasons, along a dimension from intentional to unintentional (Biehal, Mitchell and Wade, 2003). This is in line with evidence that some children appear to have voluntarily left the family home or runaway, others have drifted and become increasingly detached, while some children are forcefully removed or abducted (The Child Exploitation and Online Protection command (CEOP), 2011; Finkelhor, Hotaling, and Sedlak, 1990; Hammer, Finkelhor and Sedlak, 2002; Newiss, 2013; Newiss \& Meyer, 2005). Within their research Biehal, Mitchell and Wade (2003) identified that $70 \%$ of missing children were considered to have 'run away'. This study concentrates on the runaway subtype of missing child.

\section{Runaways}

Running away is often preceded by; conflict with parents or carers; family breakdown or poor relationships; experiences of abuse and neglect; or problems at school (Andres-Lemay, Jamieson \& MacMillan, 2005; Biehal, Mitchell, \& Wade, 2003; Kempf-Leonard \& Johansson; Lee, 2009; Meltzer, Ford, Bebbington \& Vostanis, 2012; Rees, 2011; Rees \& Lee, 2005; Social Exclusion Unit, 2002). These have been referred to in the literature as 'push factors' (Kerr \& Finlay, 2006; Kirby \& Middleham, 2005). Research has also identified that 'pull' factors (factors that make running away more appealing) also contribute to the child's decision to leave home. Examples include; leaving home to be with an older 'boyfriend', the promise of a better life or striving for independence (Scott \& Skidmore, 2006; Smeaton, 2009; Smeaton, 2013; 


\section{REPEAT MISSING CHILD REPORTS IN WALES}

Henderson \& Henderson, 1998). Other factors identified as relevant to running away include being female (Rees \& Lee, 2005; Sanchez, Waller \& Greene, 2006; Tyler \& Bersani, 2008;) and a lower socioeconomic status (Tyler \& Bersani, 2008; Rees, 2011). For a full review of risk factors relevant to running away please refer to Hutchings, Chou and Browne (2018).

Most children (77\%) missing as a result of running away return within 48 hours (Abrahams \& Mungall, 1992). However, a smaller proportion of these children chose to spend increasing amounts of time away from home. These children are more likely to become detached from their home life. These children are unlikely to seek formal support which leaves them vulnerable to the influences of 'the streets' (Smeaton, 2005). Offending behaviours or socalled 'survival crimes' serve to further marginalise this group of children, making them even less likely to seek support and thus leaving them vulnerable to the influence of anti-social or predatory others (Browne \& Falshaw, 1998; Shalev, 2011; Smeaton, 2009). Detached children report experiences of sexual exploitation, substance use, crime and homelessness (Smeaton, 2009).

The consequences to a child running away can be severe and long lasting. While children are away from home they are at risk of physical, psychological and sexual abuse (CEOP, 2011; Plass, 2007; Finkelstein, Wamsley, Currie \& Miranda, 2004). Being missing from home regularly can increase exposure to these risks and is associated with substance misuse (Browne \& Falshaw, 1998; CEOP, 2011).

The consequences of being missing from home are not just limited to that of the child. The families who are left behind have to deal with the devastating impacts including social, emotional and legal implications (Holmes, 2008). Further, when a child runs away this may prevent them from meeting their potential and their ability to develop into productive members of society which has economic and social costs for society (CEOP, 2011).

\section{Impact on Services}




\section{REPEAT MISSING CHILD REPORTS IN WALES}

In the UK, when a child runs away from home or care a multitude of professionals become involved across a variety of public services including Police, Local Authority, (Children's Services), health and education.

Upon receiving a report of a missing child, the Police are immediately responsible for investigating and safeguarding the child (alongside the Local Authority). The circumstances surrounding a missing incident report may not always be clear; Police may be unaware that the child has runaway or reasons why. The investigation procedure for children reported as missing to Police includes; conducting a risk assessment; providing the family with support; investigating the evidence and searching for the child.

Police responses focus on mitigating the harm that comes to, or is caused by, children reported missing while they are absent from home or care. Research has highlighted that social problems, such as family dysfunction and child abuse underlie children running away and add to the complexity of such cases (Dedel 2006). Therefore, other services are needed to address and manage the child's needs in these complex cases. In particular, the Local Authority (Children's Services) are involved in implementing safeguarding once the child has returned and resolving ongoing problems that may result in further runaway episodes. This is particularly true in cases where the child is in local authority/public care (Looked After Child).

Health services deal with the impact of harm, both physical and emotional, caused to the child whilst missing from home. For example, in instances where the child has been sexually exploited sexual health services and counselling services may be required. Further, education authorities will need to manage the impact of running away on engagement and attendance at school. Indeed, truancy has been associated with running away (Rees \& Lee, 2005).

Investigating missing person's cases is labour-intensive and therefore can be expensive. It was estimated that in 2010 the cost of missing children investigations conducted by the Police 


\section{REPEAT MISSING CHILD REPORTS IN WALES}

in the UK was $£ 222$ million, with $£ 1000$ being quoted as an average cost of a missing persons search (Parliamentary Panel, 2007). More recently researchers have suggested that an average missing persons case ( $<48$ hours in length) costs approximately $£ 2,415.80$ (Shalev-Greene \& Pakes, 2013). However, other costs for services such as the health, education, children services and the criminal justice system, whom are all involved in the consequences of dealing with the harm a child may have suffered whilst missing, are much more difficult to calculate.

\section{Repeat Missing Incidents}

Repeat missing incidents account for approximately 38\% of reported missing incidences (Bureau, 2014). Therefore, research suggests that there is heavy demand on public services in responding to children that are regularly reported missing as a result of running away (Hayden \& Goodship, 2013; Shalev-Greene \& Pakes, 2013).

Numerous authors have identified that repeat missing incidences are often due to a lack of support or intervention in resolving the reasons why the child went missing (Biehal, Mitchell, \& Wade, 2003; Mervyn, 2004; Rees \& Lee, 2005; Social Exclusion Unit, 2002). Despite media attention on missing child incidents, cuts to funding for service provision have occurred. This means that public services are under considerable pressure to do more with less money. It is of vital importance that early identification and intervention with 'at risk' children is undertaken to reduce harm and direct resources effectively (CEOP, 2011; Browne \& Falshaw, 1998). Identifying these children cannot be accomplished without first identifying specific characteristics or factors associated with repeat missing incidences.

There is a dearth of research identifying the multiple factors that contribute to a child going missing from their home repetitively. Earlier research has indicated that this group of children are more likely to have experienced chaotic family lives including abuse and conflict (Baker, McKay, Lynn, Schlange, \& Auville, 2003; Thompson \& Pollio 2006; Safer on the Streets, 1999; Smeaton, 2009). It has also been highlighted that a disproportionate amount of 


\section{REPEAT MISSING CHILD REPORTS IN WALES}

missing reports relate to children in local authority care with these children more likely to go missing repeatedly (Abrahams and Mungall 1992; Rees, 2011; Hayden \& Goodship, 2013). However, it is well-established that social problems rarely result from a single factor but usually from the interplay of several factors (Oriade, 2015). Significant gaps in current literature regarding factors that may contribute to a child going missing from home repetitively compared to a child who goes missing once are evident.

\section{The Missing Children's Team}

In the UK, Multi-Agency Safeguarding Hubs (MASH) have enhanced the collaboration of services for information sharing and coordinated actions to 'safeguard' child welfare and prevent individuals slipping through the safeguarding net.

In April 2013, a MASH for managing missing child incidents was implemented in the region of Gwent in Wales, namely the Missing Children's Team (MCT). Using multi-agency information (children's services, health, education and police) the MCT have generated an online database. This is where information deemed relevant to the well-being and safeguarding of an individual child can be stored on one form and utilised for a collaborative multi-agency risk assessment when a child is reported missing to Police. This online form has been referred to as the 'Missing Individual Risk Assessment Form' (MIRAF). A child's information is input onto the database if they are reported missing to Gwent Police and are considered to meet the ACPO definition of missing. As part of the MCT service, a referral is made for a return interview with an independent child welfare service.

The Gwent MCT is a unique way of managing missing child incidents and allows data relevant to safeguarding to be stored in one place in order to inform risk assessment procedures which in turn inform professional response.

\section{Current Research Aims}




\section{REPEAT MISSING CHILD REPORTS IN WALES}

The aim of this study was to explore data recorded in respect of children reported missing, as a result of running away, to Gwent Police. It was hoped that factors that are more common to children who go missing on multiple occasions ('high risk' of repeat missing incidents) versus those who go missing only once ('low risk' of repeat missing incidents) would be identified.

The main objective of this study was to develop a set of risk factors to predict repeat missing incidences, using a logistic regression method as describe by Leventhal (1988) for predicting cases of child maltreatment. These set of risk factors could be used in practice to direct resources with those identified as 'high risk' of repeat missing incidents being high priority for intervention and those identified as 'low risk' of repeat missing incidents being low priority for intervention. Known risk factors can also inform interventions with children who runaway to eliminate or ameliorate their effects and prevent repeat behaviour.

\section{Method}

\section{Data}

Data for this study were drawn from the Gwent Missing Children's Team (MCT) database, namely the MIRAF (Missing Individual Risk Assessment Form). Information is collated and input onto the MIRAF by the MCT as part of their day-to-day service. Data for the MIRAF is acquired via the below process.

1. Police receive missing child report.

2. Police working within the MCT notify the rest of team of the missing report.

3. MCT professionals search child in their relevant database systems (police, health, children's services and education) and background information is transferred onto the MIRAF.

4. Social Worker from MCT contacts family/carer to complete a telephone interview. Professional experience/training is used to guide judgement during this interaction with MIRAF items used as a guide for exploration (see Appendix 1 for list of MIRAF variables). 


\section{REPEAT MISSING CHILD REPORTS IN WALES}

5. Child is referred for a return interview with an independent service.

For this study, data from a 1-year period ( $1^{\text {st }}$ April 2013- $31^{\text {st }}$ March-2014) was analysed. This equated to 536 individual children who had been reported missing as a result of running away. For the purpose of anonymity and confidentiality, a reference number was assigned to each.

The number of times a child had been reported missing were collected from separate police databases, as this information was not available on MIRAF.

Incidence data collated from relevant databases was matched with the children reported missing. Incidence data was unavailable for 13 of the children; this reduced the sample size to 523 children reported missing.

Full ethical approval for the research was given by the University of X Research Ethics Committee. Relevant permissions were also obtained from the Gwent Missing Children's Team for existing data to be utilised for the purpose of this study.

\section{Procedures}

There were 46 variables included within the MCT database. However, only those with less than $10 \%$ missing data were analysed (for a full list of variables refer to Appendix 1). Those variables with less than $10 \%$ missing data were divided into four broad categories (see Table 1). These variables were examined to identify risk factors among the children who were reported missing once (low risk) compared to children who were reported missing more than once (high risk).

\section{Treatment of Data}

A chi-squared analysis was conducted on the data using cross-tabulations for further analysis. Positive associations between variables and the 'high risk' group were identified. Because of multiple testing and the number of chi-square tests carried out only those reaching a $1 \%$ level of significance $(\mathrm{p}<0.01$, two tailed) were noted, and those that were very highly 


\section{REPEAT MISSING CHILD REPORTS IN WALES}

significant ( $\mathrm{p}<0.001$, two tailed) were selected to be utilized in a binary logistic regression (predictor variables). The study seeks to identify risk factors and therefore if there was bias this would be against finding a significant association (preventing false positive identification of risk factor). Therefore, where data from these variables was missing, missing values were transformed into 'no' responses for all dichotomous 'yes/no' variables.

Binary logistic regression is a multivariate statistical method whereby the expected values of the response variable ('low risk' vs 'high risk') are modelled based on a combination of values taken by the predictors. The model parameters provide measures of strength of associations between the response variable and the predictor variables. The enter method was applied; all variables were added to the model simultaneously. Variables that did not show significance ( $p>.05$ ) were eliminated, on the basis that they were likely to be highly correlated with other variables in the model. Following elimination of non-significant variables, the logistic regression was re-run and this was adopted as the final model.

\section{Results}

\section{Characteristics of all children reported missing to Gwent Police as a result of running} away from $1^{\text {st }}$ April 2013- 31 ${ }^{\text {st }}$ March 2014 -(Univariate Results - see Table 1):

Incidences. All 523 children included in the analysis had been reported missing to Gwent Police in one year. It was found that 248 'high risk' children $(47 \%)$ had been reported missing more than once, of these 171 had been reported missing 3 or more times in the same period. By contrast, 275 'low risk' children (53\%) were reported missing only once. Figure 1 presents a histogram showing the number of children and frequency of missing incidents.

INSERT FIGURE 1 HERE

Demographics. The majority of children reported missing were over the age of 12 (93\%, $\mathrm{N}=498)$. This is in line with previous research that has identified adolescents as a particularly high risk of running away (Biehal, Mitchell \& Wade, 2003; Bureau, 2014; Rees, 
REPEAT MISSING CHILD REPORTS IN WALES

2011; Rees \& Lees, 2005). There was a small difference in the gender of the children with 51\% $(\mathrm{N}=270)$ being female and 49\% ( $=262)$ male. In line with demographics of the region the majority of children reported were white $(95 \%, \mathrm{~N}=490)$ and their first language was English (99\%, N=529). A minority of the children were classed as having a physical disability (12\%, $\mathrm{N}=61)$ and/or a learning disability $(14 \%, \mathrm{~N}=68)$.

Family factors. There was a general trend in the data towards difficulties within the family home including; reports of arguments within the family $(73 \%, \mathrm{~N}=363)$; a history of domestic violence within family $(60 \%, \mathrm{~N}=295)$; and a large percentage of children having experienced abuse/neglect as identified by services at some point in their lives $(63 \%, \mathrm{~N}=316)$. A smaller percentage of children were identified to be young carer's $(5 \%, \mathrm{~N}=27)$. These could be considered 'push factors' relevant to runaway behaviour.

INSERT TABLE 1 HERE

Risk of harm to themselves or others. In line with research identifying causes and consequences of being missing; violence $(51 \%, \mathrm{~N}=251)$, crime $(52 \%, \mathrm{~N}=256)$ and substance use $(54 \%, \mathrm{~N}=268)$ were present in over half of the sample. Further, suspected sexual exploitation were present in $27 \%(\mathrm{~N}=143)$ of children reported missing highlighting risks faced by these children whilst missing.

Service involvement. Interestingly, 97\% (N=519) of children reported missing to Gwent Police were already known in some capacity to social services, with 63\% ( $\mathrm{N}=308)$ being classed as open to social services. This meant that at least $63 \%$ of the children were identified by social services as warranting some sort of assessment or intervention. Indeed, $28 \%(\mathrm{~N}=151)$ were looked after children (LAC) and a further $8 \%(\mathrm{~N}=42)$ had child protection plans in place. Of those children that were looked after approximately two thirds (N=91) had experienced what was considered frequent changes in placement (18\% of total sample). 


\section{REPEAT MISSING CHILD REPORTS IN WALES}

It was highlighted that $35 \%(\mathrm{~N}=179)$ of children reported missing were known to the Youth Offending Services (YOS). This suggests that approximately 15\% of those children identified as involved in crime were not on the YOS's radar (no trace of the child on YOS's systems indicating YOS had never received a referral in respect of the child and there had never been any contact with the child). Some children $(12 \%, \mathrm{~N}=61)$ were identified as having formal boundaries (e.g. curfews, exclusions zones) in place either for the child's own safety or as a result of involvement with criminal activity (e.g. theft, violence etc). The fact that these children were reported missing suggests that they are unlikely to have been complying with these formal boundaries.

A large proportion $(74 \%, \mathrm{~N}=360)$ of children that were reported missing were identified to have had frequent Accident and Emergency (A\&E) attendances. This indicates the challenges these children are experiencing surviving in isolation of caring responsible adults and the high-risk context in terms of their safety, as well as the impact on services in dealing with the harm caused.

\section{Factors associated with repeat missing incidences (Bivariate Results - see Table 2)}

Thirteen variables associated with being reported missing more than once (high risk) were identified. These variables showed significant $(\mathrm{p}<.001$, two tailed) positive associations with repeat missing incidences determined by chi-squared analysis. These variables are listed in Table 2.

Age and repeat missing incidences. Children age 12 or older were significantly more likely to be in the 'high risk' group $(97 \%, \mathrm{~N}=241)$ compared to the 'low risk' group (89\%, $\mathrm{N}=246$ ). This difference between age groups is likely to be due to younger children having less opportunity to go missing; supervision from adults towards younger children is likely to be more intense. For example, children are expected to be escorted to and from school. 
Service involvement, family discord and repeat missing incidences. Although the vast majority of children reported missing to Gwent Police were known in some capacity to social services, a significant positive relationship was found between being known to social services and being reported missing more than once. In fact, $100 \%(\mathrm{~N}=248)$ of children belonging to the 'high risk' group were known to social services compared to 94\% ( $\mathrm{N}=258)$ of the 'low risk' group. Of these cases; $81 \%(\mathrm{~N}=182)$ of 'high risk' children were open to social services compared to $47 \%(\mathrm{~N}=119)$ of the 'low risk' group. Furthermore, $48 \%(\mathrm{~N}=118)$ of the 'high risk' group were 'Looked After Children' (LAC) in public care compared to $11 \%(\mathrm{~N}=29)$ of the 'low risk' group. For those children that were in public care, changes in placement was also significantly positively associated with being reported missing more than once; $32 \%$ $(\mathrm{N}=72)$ of the 'high risk' group compared to 6\% $(\mathrm{N}=17)$ of the 'low risk' group. This suggests significant problems in the out of home care system, placement stability and support. Results also indicate that arguments in the family are significantly more likely within in 'high risk' group $(80 \%, \mathrm{~N}=185)$ compared to the 'low risk' group $(67 \%, \mathrm{~N}=171)$.

\section{INSERT TABLE 2 HERE}

Risk of harm to themselves or others and repeat missing incidences. The risk of harm to themselves or others was significantly associated with repeat missing incidences. This included substance use, with this factor present in 71\% (N=166) of 'high risk' group compared to $38 \%(\mathrm{~N}=96)$ of the 'low risk' group. Crime, was a factor in $63 \%(\mathrm{~N}=145)$ of the 'high risk' group compared to $41 \%(\mathrm{~N}=103)$ of the 'low risk' group; and violence, was a factor in $60 \%(\mathrm{~N}=138)$ of the 'high risk' group compared to $43 \%(\mathrm{~N}=107)$ of the 'low risk' group. In line with these results children in the 'high risk' group were significantly more likely to be known to the Police and YOS $(49 \%, \mathrm{~N}=115)$ and/or to have formal boundaries $(18 \%, \mathrm{~N}=43)$ than those in the 'low risk' group $(22 \%, \mathrm{~N}=57$ and $6 \%, \mathrm{~N}=16$ respectively). However, children in the 'high risk' group were also significantly more likely to be identified 
REPEAT MISSING CHILD REPORTS IN WALES

as victims of sexual exploitation; 38\% ( $\mathrm{N}=93)$ compared to $18 \%(\mathrm{~N}=49)$ of the 'low risk' group. In addition, 73\% ( $\mathrm{N}=174)$ were identified as having experienced abuse/neglect at some point during their lives compared to $52 \%(\mathrm{~N}=134)$ of the 'low risk' group. 


\section{Predicting Repeat Missing Incidences (Logistic Regression - see Table 3)}

The 11 variables identified to have very high significant associations $(\mathrm{p}<0.0001)$ with the 'high risk' group as identified in the bivariate analyses (see Table 2) were entered into the binary logistic regression analysis (On the basis of the Bonferroni correction two variables 'arguments in family' and 'age' were eliminated). The Logistic regression on 11 variables identified only five variables were significant at the $\mathrm{p}<.05$ level for distinguishing between those who are reported missing once (low risk) from those who are reported missing more than

once (high risk). Therefore, to establish the best possible predictive accuracy; the logistic regression model was re-run using only the five significant risk factors with the other cocorrelate variables removed from the model (see Table 3).

Table 3 shows that in comparison to those 275 (53\%) children that were reported missing once (low risk), the $248(47 \%)$ children who were reported missing more than once (high risk) were; 4.9 times more likely to be a looked after child; 2.6 times more likely to have be partaking in substance use; 2.2 times more likely to have experienced abuse/neglect; 2.1 times more likely to be known by YOS; and 1.8 times more likely to have been suspected of sexual exploitation.

\section{INSERT TABLE 3 HERE}

This resulted in a logistic regression model that was able to correctly classify the outcome in $73 \%$ of cases (Table 4). More specifically, the model predicted $41 \%$ of cases in the 'high risk' group and 59\% in the 'low risk' group. It correctly specified $81 \%$ (specificity) of those who were reported missing once and was sensitive to $65 \%$ (sensitivity) of those who were reported missing more than once. However, $19 \%$ of those who were reported missing once were incorrectly classified, resulting in 52 false positives (type I error). Similarly, 35\% of those who went missing more than once were incorrectly assigned, resulting in 88 false negatives 


\section{REPEAT MISSING CHILD REPORTS IN WALES}

(type II error). In summary, there was a positive predictive accuracy for high risk cases of $75 \%$ and a negative predictive accuracy for low risk cases of $72 \%$.

INSERT TABLE 4 HERE

\section{Discussion}

This study analysed data collected by the Gwent MCT to identify characteristics or factors associated with 523 runaway missing child reports. The aim was to identify whether factors could be used to distinguish between those 248 children who were at risk of running away on two or more occasions ('high risk' of repeat missing incidents) versus those 275 children who runaway once ('low risk' of repeat missing incidents). Overall, 13 characteristics correlated with the 'high risk' group (see Table 2) but a logistic regression showed that only five factors significantly contributed to a logistic regression model, the other variables being co-correlates of these. The following five factors could distinguish those children reported missing once as a result of running away (low risk) in comparison to those reported missing more than once as a result of running away (high risk):

- Looked after child (LAC; in local authority/public care),

- History of child abuse and neglect (CAN),

- History of child sexual exploitation (CSE),

- History of Substance Abuse/misuse (SA), and

- Known to Youth Offending Services (YOS).

The results of the study initially found that the incidence of repeated missing reports was $47 \%$ and that this was significantly associated with two or more of the above risk factors being a characteristic of the missing child report. This technique would be sensitive to (and pick up) eight out of ten ( $82 \%$ ) of the 'high risk' cases but would only correctly identify $60 \%$ of the low risk cases with four out of ten low risk cases being a false alarm. Therefore, a more 


\section{REPEAT MISSING CHILD REPORTS IN WALES}

sophisticated approach is required to mirror or improve on the $73 \%$ correct classification of cases shown in the logistic regression using the five-factor model. The same risk factors have recently been identified elsewhere in the UK: Barnardo's identified the risk factors of LAC, CAN, CSE, SA (either as substance use or substance exploitation), and YOS (antisocial offending and/or criminal behaviour) as significantly associated with repeat running away (Smeaton, 2013). This may indicate that the five factor logistic regression model may be applicable for use outside of Gwent.

\section{Looked after child (LAC; in local authority/public care)}

The results of the current study indicated that Looked After Children (LAC) are significantly more likely to belong to the 'high risk' group of repeat runaway incidences. This is in line with previous research (Rees, 2011). It has been suggested that most LAC who runaway do so to seek out family members or friends which they have been separated from as a result of being placed in public (local authority) care (Biehal \& Wade, 2002; Fasulo, Cross, Mosley \& Leavey, 2002; Kerr \& Finlay, 2006). LAC may feel a greater sense of attachment to their origin families than to their current living environment and these feelings may act as 'push' factors to drive their runaway behaviour (Fasulo, Cross, Mosley \& Leavey, 2002). However, LAC generally enter into care system having come from families who are deemed unable or unwilling to provide adequate care and hence have had significant negative experiences before being looked after which may also contribute to their running away. It is also possible that children in out of home care may be reported more regularly as missing due to more vigilant reporting by carers whom are trained and expected to report children missing as a matter of protocol (CEOP, 2011).

\section{History of Child Abuse and/or Neglect (CAN)}

The results of the current study identified that children with a history of abuse/neglect were significantly associated with the 'high risk' group of repeat runaway incidences. This is 
in line with previous UK studies (Rees, 2011; Biehal \& Wade, 2000; Browne \& Falshaw, 1998). It is possible that running away may be a coping strategy that has developed in response to abusive past experiences encountered by these children and young people.

\section{History of Child Sexual Exploitation (CSE)}

In the current study CSE was found to be a significant predictor of the 'high risk' group of repeat runaway incidences. This is in line with previous research in the UK which has identified that children who are sexually exploited often go missing (CEOP, 2011; Sharp, 2012; Smeaton, 2013). It has been reported that exploiters target children deemed more vulnerable, for example those suffering bereavement or other loss, those who are experiencing difficulties within the family, with a history of abuse or those who are already accommodated in care (Scott, 2001). These children may seek out love and affection outside of their homes and are more vulnerable to grooming. An exploiter may pose as a 'boyfriend' who encourages the child to stay away from home (Smeaton, 2013).

\section{History of Substance Abuse/misuse (SA)}

Over fifty percent of children reported missing as a result of running away to Gwent Police were engaged in substance use (54\%) and crime (52\%). This is in line with previous research (Browne \& Falshaw, 1998; CEOP, 2011; Shalev, 2011; Thompson \& Pollio 2006). It may be the case that whilst the child is missing from home they are at risk of being subjected to experiences and influences where this behaviour is condoned or encouraged. The results of this study, in line with previous research, indicated that substance use is a predictor of the 'high risk' group of repeat missing incidences.

\section{Known to Youth Offending Service (YOS)}

Those children known to YOS were significantly more likely to belong to the "high risk' group of repeat missing incidences. Children may be known to YOS for a number of reasons including; involvement in crime; engaging with peers who are involved in crime; or 


\section{REPEAT MISSING CHILD REPORTS IN WALES}

demonstrating behaviours that are considered 'concerning' to others. Results of this study are in line with the findings of Smeaton (2013).

\section{Study Implications}

This study provides some guidance to identifying the children and young people more at risk of repeat missing from home as a result of running away. It offers perspective of where services across the spectrum (Children's Services, Police, counselling) might target assessment and intervention, and informs future research to better understand the factors that contribute to risk and vulnerability for this group of children. The findings indicate a different 'pathway' for single missing incidents compared to repeat incidents of running away. Hence, the 'one size fits all' approach to intervention is unlikely to be effective. A more proactive approach can be taken with those children who have two or more of the five risk factors associated with repeatedly running away from home. This enables appropriate intervention and prevention strategies to be put into place prior to these children running away again.

The majority of children belonging to the 'low risk' group were living with family and were significantly less likely to be engaged in substance use or criminal activity. This suggests that they may be more amenable to less intensive, early, family-based intervention strategies aimed at preventing future missing incidences. Interventions aimed at this 'low risk' group should look to reduce negative interactions and resolve conflicts. An interview with the child to identify and deal with any harm they may have suffered whilst missing and to understand the reasons for the missing incident; namely return interviews, are advised in UK statutory guidance (Department of Education, 2014). These return interviews provide an opportunity to intervene with this group by providing a format within which issues contributing to the missing incidence can be explored, mediated and resolved and where needed to negotiate a successful return home. 


\section{REPEAT MISSING CHILD REPORTS IN WALES}

Children within the 'high risk' group would warrant more intensive and comprehensive intervention to counter the factors that contributed to their repeat runaway incidences. This research alongside existing literature confirms that a number of factors contribute to a child running away. Therefore, professional input from a range of services is likely to be required when intervening with this vulnerable group. Despite guidance advocating a multi-agency approach (Department of Education, 2014), the majority of services in the UK have previously worked in relative isolation when dealing with these 'high risk' children. Within Gwent (Wales) a novel approach to managing missing children is being undertaken in the form of a multi-agency team. This is enabling a multi-disciplinary risk assessment process, incorporating data from a range of services. Specialist services that focus on; substance use; the effects of physical and sexual abuse and/or exploitation; and criminal activity are especially needed for this group and should form part of a multi-agency support package.

Of special consideration for this client group is that of emotional attachment in relationships. Research has demonstrated that the most common reasons for going missing relate to problems within family relationships (Rees, 2011; Safer on the Streets, 1999; Thompson \& Pollio 2006), which was also found in this study. Indeed, a relationship between being missing, specifically running away, and the quality of parental attachment has been found (McGarvey, Keller, Brown, DeLonga, Miller, Runge \& Koopman, 2010). A specific type of attachment informed therapy, Dyadic Developmental Psychotherapy (DDP), is proving useful with children who have experienced trauma or separation within their attachment relationships (Becker-Weidman, 2006; Becker-Weidman, 2008). DDP aims to support children in feeling safe and building trust with parents or carers by enhancing sensitive and emotionally attuned care (Hughes, Golding \& Hudson, 2015). It has been identified that building strong and positive relationships within care placements is essential to preventing repeat missing incidences; specifically running away from local authority care (Biehal \& Wade, 2002; Finkelstein, 


\section{REPEAT MISSING CHILD REPORTS IN WALES}

Wamsley, Currie \& Miranda, 2004). Therefore, enhancing relationships through attachment informed therapies such as DDP may support the reduction of missing incidences within this vulnerable group.

\section{Limitations and Future Research}

The main limitation in this study was the reliability of data entry and missing data. At the time of data collection the MCT was a new team that were essentially developing their role 'on the job'. This resulted in a vast quantity of data being collated and entered by the team in a short period at the same time as training on how to collate and input information. The problem of missing data prevented the exploration of educational variables. Future research may benefit from analysing these variables as previous research suggests that problems at school are predictive of running away (Rees, 2011; SEU, 2002; Thompson \& Pollio 2006). Once a more complete dataset is established, which includes educational variables, its significance within the current 5 risk factor model can be analysed. In addition, it is important to note that the study was limited to 1 years' worth of data. Future studies may benefit from a more a more longitudinal dataset.

This study primarily identified factors that contribute to repeat episodes of running away. Research indicates that protective factors reduce or prevent vulnerability or level of risk (Rogers, 2000). This is achieved by protective factors either reducing the effect of risk factors (e.g., Clayton, Leukefeld, Donohew, Bardo, \& Harrington, 1995) or by exerting an independent influence on the outcome (e.g. Hoge, Andrews, \& Leschied, 1996). Research literature suggests that positive family relationships and engagement with school could potentially act as protective factors (Rees, 2011; Oriade, 2015). Future research may benefit from further exploration of these potential protective factors. Expanding the base of evidence will support development of more effective interventions.

\section{Conclusion}




\section{REPEAT MISSING CHILD REPORTS IN WALES}

Results of this research has highlighted a five variable logistic regression model that can distinguish single ('low risk') versus repeat ('high risk') missing reports, as a result of running away, of children in Gwent. The five significant risk factors identified by logistic regression could potentially be used to guide service intervention strategies and to direct/prioritise resources. Further research is required using similar methods to confirm the identified risk factors can be used in other areas of the UK and abroad. 


\section{REPEAT MISSING CHILD REPORTS IN WALES}

\section{References}

Abrahams, C. \& Mungall, R. (1992). Runaways: exploding the myths. London: NCH Action for Children.

ACPO (2010). Guidance on the Management, Recording and Investigation of Missing Persons. London, ACPO.

Andres-Lemay, V. J., Jamieson, E., \& MacMillan, H. L. (2005). Child abuse, psychiatric disorder, and running away in a community sample of women. The Canadian Journal of Psychiatry, 50(11), 684-689.

Baker, A. J., McKay, M. M., Lynn, C. J., Schlange, H., \& Auville, A. (2003). Recidivism at a shelter for adolescents: First-time versus repeat runaways. Social Work Research, 27(2), 84-93.

Becker-Weidman, A. (2006). Treatment for children with trauma-attachment disorders: Dyadic developmental psychotherapy. Child and Adolescent Social Work Journal, 23(2), 147171.

Becker-Weidman, A., \& Hughes, D. (2008). Dyadic developmental psychotherapy: an evidence-based treatment for children with complex trauma and disorders of attachment. Child \& Family Social Work, 13(3), 329-337.

Biehal, N. \& Wade, J. (2002) Children Who Go Missing: Research, Policy and Practice. London: Department of Health.

Biehal, N., Mitchell, F., \& Wade, J. (2003). Lost from View: Missing Persons in the UK. Bristol: Policy Press.

Browne, K., \& Falshaw, L. (1998). Street children and crime in the UK: A case of abuse and neglect. Child Abuse Review, 7(4), 241-253.

Bureau, U. M. P. (2014). Missing Persons: Data and Analysis 2012/2013. London: National Crime Agency. 


\section{REPEAT MISSING CHILD REPORTS IN WALES}

CEOP. (2011). Scoping Report on Missing and Abducted Children. London, UK: Child Exploitation Protection Centre.

Clayton, R. R., Leukefeld, C. G., Donohew, L., Bardo, M., \& Harrington, N. G. (1995). Risk and protective factors: A brief review. Drugs \& Society, 8(3-4), 7-14.

Department for Education. (2013b) Statutory guidance on children who run away or go missing from home or care. HMSO, London.

Diamond, G., Russon, J., \& Levy, S. (2016). Attachment-Based Family Therapy: A Review of the Empirical Support. Family process, 55(3), 595-610.

Fasulo, S. J., Cross, T. P., Mosley, P., \& Leavey, J. (2002). Adolescent runaway behavior in specialized foster care. Children and Youth Services Review, 24(8), 623-640.

Finkelstein, M., Wamsley, M., Currie, D., \& Miranda, D. (2004). Youth who chronically AWOL from foster care: Why they run, where they go, and what can be done. Vera Institute of Justice: NYC Administration for Children's Services.

Hayden, C., \& Goodship, J. (2013). Children reported 'missing'to the police: is it possible to 'risk assess' every incident?. British Journal of Social Work, bct150.

Henderson M \& Henderson P 1998. Missing people: issues for the Australian community. Canberra: Commonwealth of Australia.

Hoge, R. D., Andrews, D. A., \& Leschied, A. W. (1996). An investigation of risk and protective factors in a sample of youthful offenders. Journal of Child Psychology and Psychiatry, 37(4), 419-424.

Holmes, L. (2008). Living in Limbo: The Experiences Of, and Impacts On, the Families of Missing People. Missing People.

Hughes, D., Golding, K. S., \& Hudson, J. (2015). Dyadic Developmental Psychotherapy (DDP): the development of the theory, practice and research base. Adoption \& Fostering, 39(4), 356-365. 


\section{REPEAT MISSING CHILD REPORTS IN WALES}

Hutchings, E., Chou, S and Browne, K.D. (2018). 'Risk Factors associated with Running Away: A Systematic Review'. Trauma, Violence and Abuse (In Submission).

Kempf-Leonard, K., \& Johansson, P. (2007). Gender and runaways risk factors, delinquency, and juvenile justice experiences. Youth Violence and Juvenile Justice, 5(3), 308-327.

Kerr, J., \& Finlay, J. (2006). Youth Running From Residential Care:" The Push" and" The Pull". Relational child and youth care practice, 19(1), 6.

Kirby, S., \& Middleham, N. (2005). Reducing misery and saving money-how partners can make a difference in reducing the incidence of young runaways. Safer Communities, 4(4), 10-13.

Leventhal, J. M. (1988) Can child maltreatment be predicted during the perinatal period: Evidence from longitudinal cohort studies?, Journal of Reproductive and Infant Psychology, 6:3, 139-161.

Meltzer, H., Ford, T., Bebbington, P., \& Vostanis, P. (2012). Children who run away from home: Risks for suicidal behavior and substance misuse. Journal of Adolescent Health, 51(5), 415-421.

Mervyn, P (2004). Young runaways in Greater Merseyside. London: The Children's Society.

Oriade, Michael A. (2015). Predictors of recidivism among runaway and homeless youths. Ann Arbor: Capella University, 2015.

Parliamentary Panel (2007) Safeguarding Children and Young People who Runaway or Go Missing from Home or Care. London: Parliament.

Plass, P. S. (2007). Secondary Victimizations in Missing Child Events. American Journal of Criminal Justice, 32(1-2), 30-44.

Rees, G. (2011). Still Running III: Early findings from our third national survey of young runaways. London: The Children's Society. 


\section{REPEAT MISSING CHILD REPORTS IN WALES}

Rees, G. and Lee, J. (2005) Still Running II: Findings from the second national survey of young runaways. London: The Children's Society.

Rogers, R. (2000). The Uncritical Acceptance of Risk Assessment in Forensic Practice. Law and Human Behavior, 24(5), 595-605.

Sanchez, R. P., Waller, M. W., \& Greene, J. M. (2006). Who runs? A demographic profile of runaway youth in the United States. Journal of Adolescent Health, 39(5), 778-781.

Scott, S (2001) Barnardo's PHASE project: a case study evaluation. University of Liverpool: Liverpool.

Scott, S., \& Skidmore, P. (2006). Reducing the Risk: Barnardo's Support for Sexually Exploited Young People: a Two-year Evaluation. Summary Report. Barnardo's.

Shalev Greene, K. and Pakes, F. (2013). Absent: An Exploration of Common Police Procedures for Safeguarding Practices in Cases of Missing Children and Adults. Portsmouth: University of Portsmouth.

Shalev, K. (2011). Children who go missing repeatedly and their involvement in crime. Int'l J. Police Sci. \& Mgmt., 13, 29.

Sharp, N. (2012). Still Hidden. Going Missing as an indicator of child sexual exploitation. London: Missing People.

Smeaton, E. (2009). Off the Radar: Children and Young People on the Streets in the UK. London: Railway Children.

Smeaton, E. (2013). Running from hate to what you think is love: The relationship between running away and child sexual exploitation. Ilford: Barnardo's.

Social Exclusion Unit (SEU, 2002) Young Runaways. London: Social Exclusion Unit.

Thompson, S. J., \& Pollio, D. E. (2006). Adolescent runaway episodes: Application of an estrangement model of recidivism. Social Work Research,30 (4), 245-251. 
REPEAT MISSING CHILD REPORTS IN WALES

Tyler, K. A., \& Bersani, B. E. (2008). A longitudinal study of early adolescent precursors to running away. The Journal of early adolescence, 28(2), 230-251. 
REPEAT MISSING CHILD REPORTS IN WALES

Table 1

Data collected by the Missing Children's Team on children reported missing as a result of running away to Gwent Police 2013-2014 (N=523)

\begin{tabular}{|c|c|c|c|}
\hline Variable & Valid N & Yes $(\%)$ & No $(\%)$ \\
\hline \multicolumn{4}{|l|}{ Demographics } \\
\hline Age $\geq 12$ years old & 536 & 93 & 7 \\
\hline Female & 520 & 51 & 49 \\
\hline White & 505 & 95 & 5 \\
\hline English language & 523 & 99 & 1 \\
\hline Physical disability & 487 & 12 & 88 \\
\hline Learning disability & 483 & 14 & 86 \\
\hline \multicolumn{4}{|l|}{ Family factors } \\
\hline Arguments in family & 494 & 73 & 27 \\
\hline History of child abuse/neglect & 505 & 63 & 37 \\
\hline History of domestic abuse & 480 & 60 & 40 \\
\hline Young carer & 495 & 5 & 95 \\
\hline \multicolumn{4}{|l|}{ Risk of harm to themselves or others } \\
\hline Violence & 492 & 51 & 49 \\
\hline Crime & 494 & 52 & 48 \\
\hline Substance abuse/misuse & 496 & 54 & 46 \\
\hline Suspected child sexual exploitation & 533 & 27 & 73 \\
\hline \multicolumn{4}{|l|}{ Service involvement } \\
\hline Known to social services & 535 & 97 & 3 \\
\hline *Open to social services & 491 & 63 & 37 \\
\hline Protection plan & 500 & 8 & 92 \\
\hline Known to Youth Offending Services & 505 & 35 & 65 \\
\hline Looked after child & 535 & 28 & 72 \\
\hline Formal boundaries in place (e.g. curfew) & 504 & 12 & 88 \\
\hline Changes in placement & 498 & 18 & 82 \\
\hline Frequent A\&E attendances & 474 & 74 & 26 \\
\hline
\end{tabular}

Note. $\mathrm{N}=$ number of children 
REPEAT MISSING CHILD REPORTS IN WALES

*Open to social services: an 'open' case currently active with a social worker allocated, either being worked as child in need, child protection, looked after (section 20 and 31) or aftercare. 


\section{REPEAT MISSING CHILD REPORTS IN WALES}

Table 2

Factors for children being reported missing ${ }^{a}$

\begin{tabular}{|c|c|c|c|c|}
\hline Variables & $\begin{array}{l}N(\text { Total } \\
=523)\end{array}$ & $\begin{array}{c}\text { Children reported missing } \\
\text { once }(\%)\end{array}$ & $\begin{array}{c}\text { Children reported missing } \\
\text { more than once }(\%)\end{array}$ & $\begin{array}{c}\text { Chi }^{2} \text { value } \\
(d f=1)\end{array}$ \\
\hline Age $\geq 12$ years & 523 & 89 & 97 & $23.92^{*}$ \\
\hline Arguments in family & 484 & 67 & 80 & $10.67 * *$ \\
\hline History of child abuse/neglect & 494 & 52 & 73 & $23.78 * * *$ \\
\hline Violence & 480 & 43 & 60 & $14.18 * * *$ \\
\hline Crime & 482 & 41 & 63 & $21.84 * * *$ \\
\hline Substance abuse/misuse & 485 & 38 & 71 & $53.56 * * *$ \\
\hline Suspected child sexual exploitation & 520 & 18 & 38 & $24.81 * * *$ \\
\hline Known to social services & 522 & 94 & 100 & $14.94 * * *$ \\
\hline Open to social services & 479 & 47 & 81 & $61.08 * * *$ \\
\hline Looked after child & 522 & 11 & 48 & $88.08 * * *$ \\
\hline Changes in placement & 486 & 6 & 32 & $53.79 * * *$ \\
\hline Known to Youth Offending Services & 494 & 22 & 49 & $39.37 * * *$ \\
\hline Formal boundaries in place & 493 & 6 & 18 & $17.65 * * *$ \\
\hline
\end{tabular}

Note. $\mathrm{N}=$ number of children, $\mathrm{df}=$ degrees of freedom

${ }^{a}$ As identified by $\mathrm{Chi}^{2}$ analysis 
REPEAT MISSING CHILD REPORTS IN WALES

$* \mathrm{p}<.01, * * \mathrm{p}<.001, * * * \mathrm{p}<.0001$ 
REPEAT MISSING CHILD REPORTS IN WALES

Table 3

Binary logistic regression for 'high risk' children $(N=523)$

\begin{tabular}{ccc}
\hline Variable & Odds Ratio & S.E. \\
\hline History of child abuse/neglect & $2.23^{* * *}$ & .21 \\
Substance abuse/misuse & $2.59^{* * *}$ & .22 \\
Suspected child sexual exploitation & $1.80^{*}$ & .23 \\
Known to YOS & $2.14^{* *}$ & .23 \\
Looked after child & $4.92 * * *$ & .25 \\
\hline
\end{tabular}

Note: $\mathrm{S} . \mathrm{E}=$ standard error

$* \mathrm{p}<.05, * * \mathrm{p}<.001, * * * \mathrm{p}<.0001$ 
REPEAT MISSING CHILD REPORTS IN WALES

Table 4

Classification of children who were reported missing once or more than once $(N=523) *$

\begin{tabular}{cccc}
\hline $\begin{array}{c}\text { Actual Missing Report } \\
\text { Incidences }\end{array}$ & 1 (Low Risk) & $>1$ (High Risk) & Actual Total \\
\hline 1: Once & $223(81 \%)$ & $52(19 \%)$ & $275(100 \%)$ \\
$>1$ : More than once & $88(35 \%)$ & $160(65 \%)$ & $248(100 \%)$ \\
Predicted total & $311(59 \%)$ & $212(41 \%)$ & $523(100 \%)$ \\
\hline
\end{tabular}

Note. $\mathrm{N}=$ number of children

$* 73 \%$ correct classification 


\section{REPEAT MISSING CHILD REPORTS IN WALES}

Figure 1. A histogram showing the number of children and frequency of missing incidents

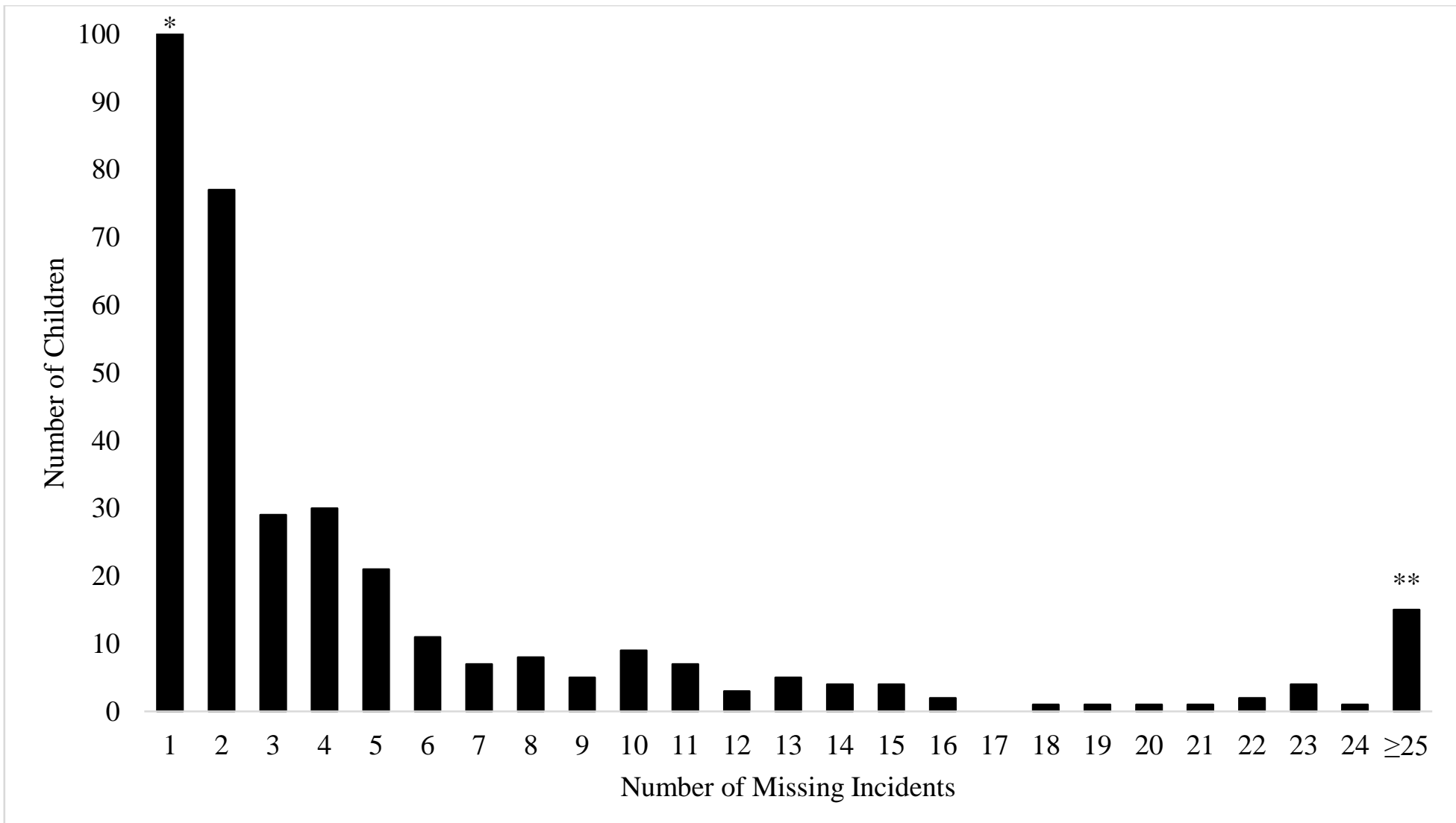

$*$ Total frequency with one missing incidence $=275, * * 25-69$ incidents 


\section{Appendix 1}

Full list of variables used by the Gwent Missing Children's Team:

- Age

- Gender

- Ethnicity

- Language

- Religion

- Known to Social Services

- Open to Social Services

- Looked After Child

- History of abuse or neglect

- Protection plan in place

- Frequent changes in placement

- Conflict in placement

- Known to Youth Offending Service

- Other services involved

- Frequent A\&E attendances

- Physical disability or illness

- Engaged with sexual health services

- Sexually active

- Self-harm

- Mental illness

- Depression

- Mentally ill parent
- Poor school attendance

- Educational statement

- Bullying

- Specialist education

- Learning Disability

- Domestic violence within parental relationships

- Substance misuse

- Substance misusing parent

- Criminal child

- Criminal parent

- Previous victim

- Violent

- Family scapegoating

- Arguments within family

- Older boyfriend/girlfriend

- Risky internet use

- Suspected sexual exploitation

- Evidence of trafficking

- Young carer

- Boundaries in place

- Support network

- Formal boundaries in place

- Receiving direct work

- Engaged in positive social activities 